\title{
FRESH PORCINE CARDIAC VALVES ARE NOT REJECTED IN PRIMATES
}

Raymond H. Chen, MD, PhD ${ }^{\mathrm{a}}$

Alexander Kadner, $\mathrm{MD}^{\mathrm{a}}$

Richard N. Mitchell, MD, $\mathrm{PhD}^{\mathrm{b}}$

David H. Adams, MD ${ }^{a}$
Objective: Transplanted porcine hearts are hyperacutely rejected by human immunoglobulin $\mathrm{M}$ antibodies against a porcine vascular endothelial molecule, galactose $\alpha$-1,3-galactose, with ensuing human complement activation and membrane attack complex deposition. It is unclear, however, whether porcine valve endothelium triggers a similar immune response. We sought to investigate whether fresh porcine valves implanted into primates are rejected.

Methods: Wild-type porcine hearts before $(n=6)$ and after $(n=3)$ heterotopic transplantation into baboons underwent sectioning and were examined by hematoxylin and eosin staining and immunohistochemistry for galactose $\alpha-1,3$-galactose, primate immunoglobulin $\mathrm{M}$, and membrane attack complex.

Results: Examination of untransplanted porcine hearts showed that although cardiac microvascular endothelium strongly expressed the galactose $\alpha-1,3$ galactose antigen, galactose $\alpha$-1,3-galactose was not detected on the endothelium of porcine aortic and pulmonary valves. Porcine hearts transplanted into baboon recipients were hyperacutely rejected 60 to 80 minutes after implantation. Despite dramatic tissue damage associated with extensive immunoglobulin $\mathrm{M}$ and membrane attack complex binding on the microvascular endothelium, the aortic and pulmonary valves were entirely spared. Valves remained morphologically intact at explant and showed no signs of immunoglobulin M- and membrane attack complex-mediated damage.

Conclusions: The absence of galactose $\alpha$-1,3-galactose expression may protect unfixed porcine valves from xenograft rejection in primates. Further investigation of viable porcine valves appears warranted. ( $\mathrm{J}$ Thorac Cardiovasc Surg 2000;119:1216-20)
$\mathrm{D}$ iseased cardiac valves are replaced with either mechanical or biologic tissue prostheses. Mechanical valves are more durable but require long-

From the Departments of Surgery ${ }^{\mathrm{a}}$ and Pathology, ${ }^{\mathrm{b}}$ Brigham \& Women's Hospital, Harvard Medical School, Boston, Mass.

Dr Chen is an American College of Surgeons Research Scholar 1998-00 and recipient of National Institutes of Health Individual National Research Service Award (NRSA) 1F32HL0996601. This work is supported by a Nextran, Inc, sponsored research grant. Primate quarantine work was supported by the New England Primate Research Center grant P51RR00168-37.

Received for publication Dec 8, 1999; accepted for publication Feb $14,2000$.

Address for reprints: David H. Adams, MD, Division of Cardiac Surgery, Brigham \& Women's Hospital, 15 Francis St, Boston, MA 02115 (E-mail: dadams@partners.org).

Copyright (C) 2000 by The American Association for Thoracic Surgery

$0022-5223 / 2000 \$ 12.00+0 \quad \mathbf{1 2 / 1 / 1 0 6 5 2 6}$

doi:10.1067/mtc. 2000.106526 term anticoagulation therapy to prevent surface clotting. Risks associated with anticoagulation therapy, such as bleeding or thromboembolism, are of concern to many patients. Although biologic tissue valves do not require anticoagulation therapy, their durability is limited by structural degeneration, calcification, or both. ${ }^{1}$

It is unclear whether the degeneration of porcine valve prostheses is mediated by immune rejection. Porcine hearts transplanted into human subjects prompt a violent hyperacute rejection similar to that seen in ABO-incompatible transplantation in which the graft becomes cyanotic and edematous minutes after implantation. ${ }^{2}$ The mechanism of porcine tissue rejection was elucidated in 1987, when Galili and colleagues ${ }^{3}$ showed that human subjects constitutively synthesize immunoglobulin (Ig) $\mathrm{M}$ natural antibodies against a porcine endothelial molecule, galactose $\alpha$-1,3-galactose $(\alpha-G a l)$. The extensive microvascular thrombosis of 


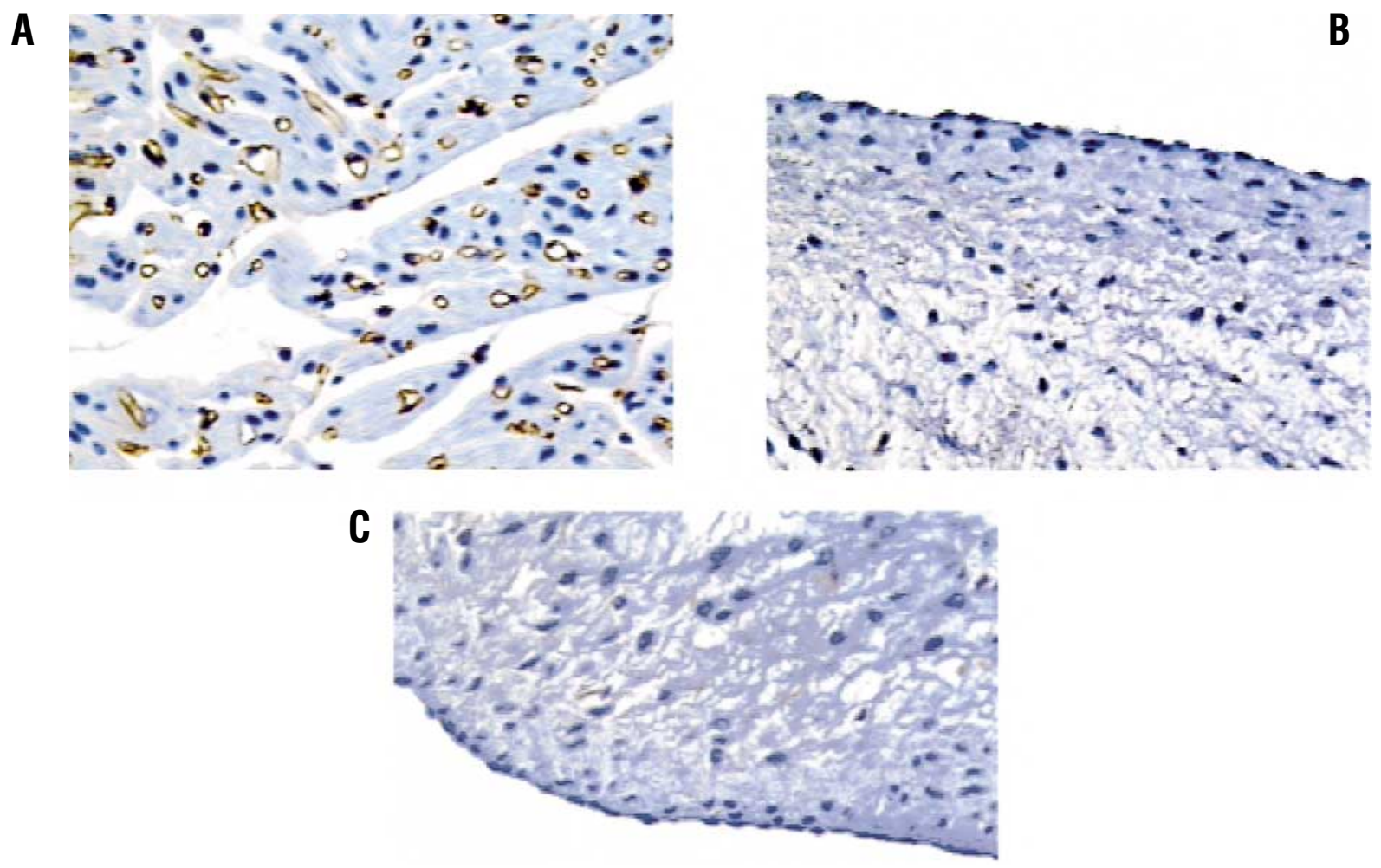

Fig 1. Differential $\alpha$-Gal expression on the endothelium of porcine valve leaflets versus microvasculature. Untransplanted porcine hearts were examined for the expression of $\alpha$-Gal. Porcine microvascular endothelium show strong $\alpha$-Gal expression (A). On the other hand, neither porcine aortic valves (B) nor pulmonary valves (C) showed any detectable $\alpha$-Gal expression.

hyperacute rejection is the result of IgM-triggered, complement membrane attack complex (MAC)-mediated graft destruction.

Because the mechanism of the human anti-pig immune response is now understood, we sought to determine whether human subjects mount a rejection response against fresh porcine valves. We suspected that valves may be immunologically distinct from heart tissue. Previously, Mitchell and colleagues ${ }^{4}$ had shown that cardiac valves, even in rejected human heart transplants, rarely show any cellular infiltrate. Therefore, it may be possible that valves, as nonvascularized tissue, may be a low-visibility target for the immune system. The potential immune privilege of valve tissue suggests that porcine valve tissue may survive in human recipients. We thus sought to investigate the possibility of implanting fresh porcine valves. Fresh porcine valves contain viable endothelial and fibroblast cells, which can continuously repair leaflets undergoing hemodynamic stress and possibly confer better long-term durability. $^{5}$
To examine the immune reaction against fresh porcine valves, we performed heterotopic pig-tobaboon cardiac xenotransplantation. Relative expression of $\alpha$-Gal antigens on vascular and valve endothelium was evaluated, and the degree of IgM and MAC deposition on valve leaflets was compared with that on cardiac microvasculature.

\section{Material and methods}

Experimental animals. Heterotopic pig-to-primate cardiac xenotransplantation was performed to test the immune reaction against fresh, unmanipulated, porcine valves. Olive baboons (Papio anubis) served as transplant recipients, whereas wild-type (Parson Farm) pigs served as heart donors. No immunosuppression was used for the study. All animals received humane care in accordance with the guidelines of the Harvard University Animal Care Committee and the "Guide for the Care and Use of Laboratory Animals" prepared by the Institute of Laboratory Animal Resources and published by the National Academy Press (National Academy Press publications No. xii-125, revised 1996). 
Anesthesia. For invasive procedures and anesthesia induction, sedation was achieved by using ketamine hydrochloride $(10 \mathrm{mg} / \mathrm{kg}$ administered intramuscularly) in baboons and tiletamine hydrochloride and zolazepam hydrochloride (Telazol; 5 $\mathrm{mg} / \mathrm{kg}$ administered intramuscularly) in pigs. Respiratory secretions were controlled with atropine sulfate $(0.03 \mathrm{mg} / \mathrm{kg})$. Anesthesia was maintained with inhalational isoflurane (1.3\%$2.0 \%$ ). Intraoperatively, both pigs and baboons were monitored with electrocardiography, noninvasive blood pressure monitoring, and pulse oximetry. All baboons received antibiotic coverage with cefazolin (Ancef; $20 \mathrm{mg} / \mathrm{kg}$ administered intramuscularly twice daily) and pain control with butrenorphine (Buprenex; $0.005 \mathrm{mg} / \mathrm{kg}$ administered twice daily) postoperatively for 5 days. In the event of diminished fluid or caloric intake, recipients received their calculated daily needs as intravenous crystalloid solution or Ensure tube feeds.

Heterotopic heart transplantation model. Heart transplantation was performed in the abdominal cavity, as previously described. ${ }^{6}$ Pigs were anesthetized and received systemic anticoagulation with heparin (100 IU/kg administered intravenously), after which the heart was harvested in a standard fashion after protection by $500 \mathrm{~mL}$ of antegrade cold crystalloid cardioplegic solution (dextrose, $2.5 \%$; sodium chloride, $0.45 \%$; potassium, $30 \mathrm{mEq} / \mathrm{L}$; and bicarbonate, $5 \mathrm{mEq} / \mathrm{L}$ ). Transplant organ ischemic time varied between 45 and 55 minutes. The animals received no immunosuppression.

Histopathologic studies of the porcine valves. After graft explantation, aortic and pulmonary valves were carefully dissected and either snap-frozen in Tissue Freezing Medium (Triangle Biomedical Sciences, Durham, NC) and liquid nitrogen or fixed in Carnoy solution and embedded in paraffin. Paraffin sections were sectioned at $5-\mu \mathrm{m}$ thickness and stained with hematoxylin and eosin. Biotinylated lectin from Griffonia simplicifolia (Sigma, St Louis, Mo) was used to stain $\alpha$-Gal on porcine endothelium. Cryostat sections were immunostained by use of standard indirect immunoperoxidase avidin-biotin techniques, as previously summarized, ${ }^{7}$ with monoclonal antibodies specific for IgM (Biodesign International, Kennebunk, Me) and MAC (C5-9; Dako, Carpinteria, Calif). The signal was developed with the avidinperoxidase system (ABC kit; Vector Lab, Burlingame, Calif).

\section{Results}

Endothelium of porcine valves and cardiac microvasculature. We examined untransplanted porcine hearts $(n=6)$ to characterize $\alpha$-Gal expression on the endothelium of valve leaflets and cardiac microvasculature. Cardiac microvascular endothelium showed strong $\alpha$-Gal expression (Fig 1, A). In comparison, neither aortic valves (Fig $1, B$ ) nor pulmonary valves (Fig $1, C$ ) showed any detectable $\alpha$ Gal expression.

Porcine valves in hyperacute rejection. Wild-type porcine xenografts $(n=3)$ were hyperacutely rejected 60 to 80 minutes after implantation into baboons with- out immunosuppression. The hearts became edematous, cyanotic, and engorged. Histologic examination of the rejected graft showed signs of thrombi, interstitial hemorrhage, and edema. There was extensive microvascular IgM (Fig 2, A) and MAC (Fig 2, B) deposition on the microvascular endothelium. Interestingly, both aortic and pulmonary valves were intact, and immunohistochemistry of pulmonary and aortic valves showed no signs of either IgM (Fig 2,C) or MAC (Fig 2, D).

\section{Discussion}

The use of animal valve prostheses was first proposed and tested during the 1940s and 1950s. Although the exact immune barriers of animal-to-human tissue transplantation were not understood at that time, failures of organ transplantation convinced many that valve transplantation would suffer the same fate. Because of the difficult immunologic barriers of crossspecies transplantation, efforts were focused on preparing valves resistant to immune rejection. Fixatives were introduced not as a method of decreasing antigenicity but as a sterilizing and stiffening agent. In the first experimental article describing the transplantation of porcine valves, Duran and Gunning ${ }^{8}$ mentioned that "the (porcine) graft was sterilized by immersion in liquid ethylene oxide." The other pioneers in the field, Binet and colleagues, ${ }^{9}$ described "non-sterile pig and calf aortic valves obtained immediately after death at the slaughter house was at once placed in a mercurial solution" for 3 days. Only after that were the valves transferred into "sterile Gross's solution." The first reported use of formaldehyde on valves was to denature and stiffen elastic fibers in human homografts. ${ }^{10}$ The first formaldehyde preservation of porcine valves was performed by O'Brien, ${ }^{11}$ who used the solution in 1967 for "both preservation and sterilization." Both Hamilton and Gerbode ${ }^{12}$ and Paneth and O'Brien ${ }^{10}$ hypothesized that because formaldehyde "de-natures the proteins of the graft, [it] may minimize rejection phenomenon." However, there was no experiment or data to support this hypothesis.

A legacy of these early pioneers is glutaraldehydefixed porcine valves, which have successfully served as valve prostheses for the past 40 years. However, these valves degenerate because of hemodynamic stress and calcification. Fresh porcine valves may help to prevent both problems. Fresh valves contain viable endothelial and fibroblast cells, which may continue to repair and modify the leaflets undergoing hemodynamic stress and possibly confer better long-term durability. ${ }^{5}$ Historically, fresh valves have not been seriously con- 

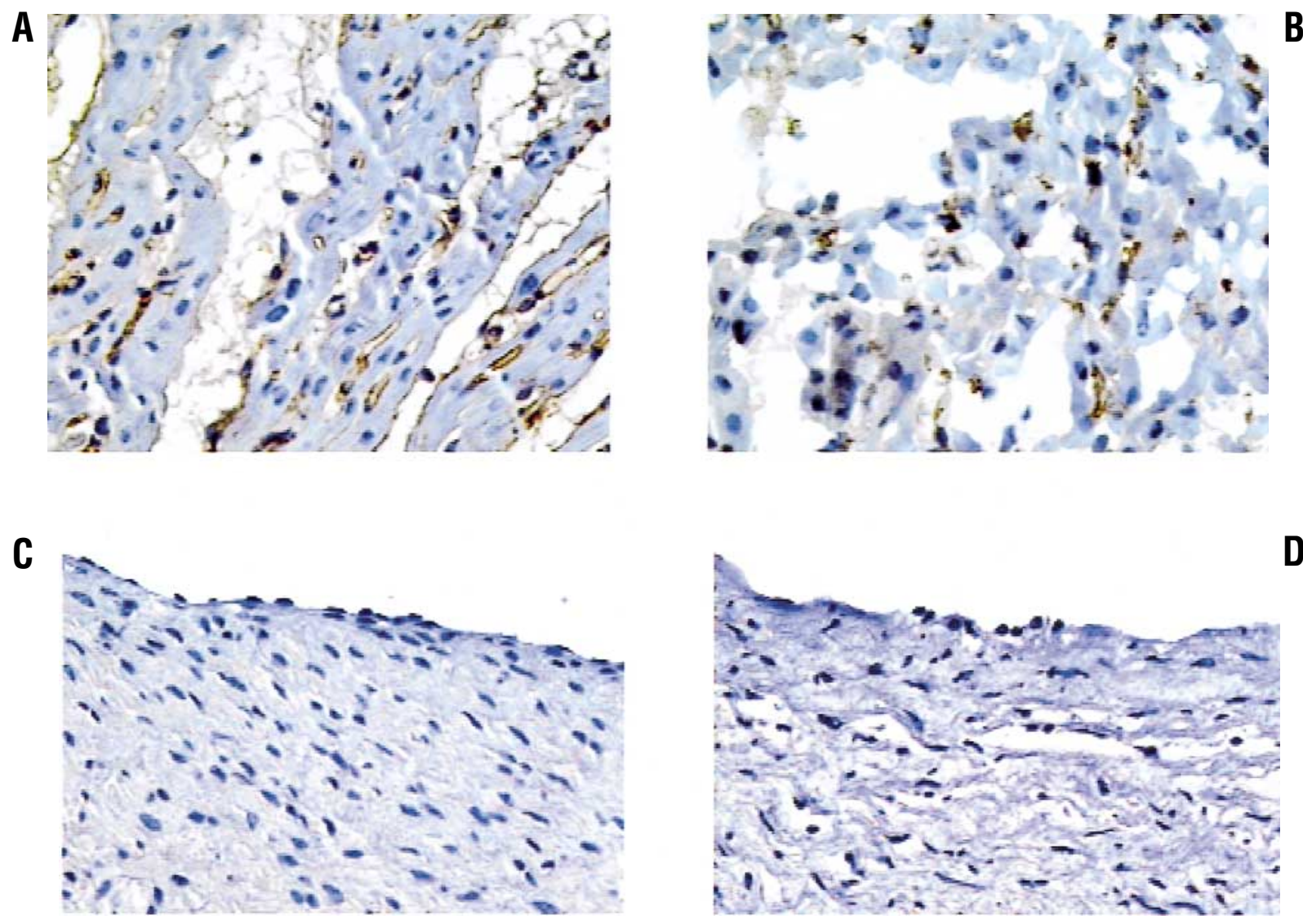

Fig 2. Porcine valves in hyperacute rejection. Wild-type pig hearts $(n=3)$ were transplanted into unmodified baboon recipients. There was extensive microvascular IgM (A) and MAC (B) deposition on the cardiac microvascular endothelium. The aortic valves inside the xenografts, however, showed no signs of either IgM (C) or MAC (D) deposition.

templated as possible valve prostheses, mainly because of the assumption that all fresh porcine tissue, whether myocardium or cardiac valves, would undergo rejection.

In this report, however, we found that porcine valvular leaflets do not express $\alpha$-Gal on their endothelium. The absence of detectable $\alpha$-Gal on valvular leaflets may have protected porcine valves from IgM-mediated hyperacute rejection. Consequently, even though wildtype porcine cardiac xenografts were destroyed within 60 to 80 minutes of implantation by severe IgM and MAC deposition, aortic and pulmonary valves harvested from rejected xenografts showed no sign of damage.

The difference of $\alpha$-Gal expression among different endothelial layers was not totally unexpected because we previously found that the endothelial cells of porcine cardiac microvasculature express $\alpha$-Gal, whereas those of larger vessels do not. ${ }^{7}$ Decreased $\alpha-G a l$ expression on valve endothelium could be due to either decreased glycosylation or decreased surface glycoproteins on leaflet endothelium. Protein expression is closely regulated in endothelial cells, and flow rate can clearly modulate endothelial gene expression. The expression of proteins, such as major histocompatibility complex antigen ${ }^{13}$ and vascular cell adhesion molecule $1,{ }^{14}$ are all influenced by the amount of shear force exerted on the endothelium. Consequently, it is possible that shear force may also modulate other genes, such as the gal $\alpha-1,3$-galactosyltransferase gene. The gal $\alpha$-1,3-galactosyltransferase protein glycosylates the $\alpha$-Gal terminal sugar to surface proteins, ${ }^{15}$ and its expression is tightly controlled in the porcine endothelium. For example, inflammatory cytokines, such as tumor necrosis factor $\alpha$ and lipopolysaccharide, decrease the level of gal $\alpha-1,3$ galactosyltransferase protein. Consequently, it is possible that differential shear forces exerted on cardiac 
valvular endothelium may influence gal $\alpha$-1,3-galactosyltransferase gene expression and reduce Gal production along the vascular system.

Alternatively, the differential Gal staining may be reflective of the level of expression of glycoproteins on porcine endothelium. Holzknecht and Platt ${ }^{16}$ showed that the majority of porcine Gal epitopes bound by human xenoreactive antibodies are found on the von Willebrand factor and the integrin family $\alpha_{1}, \alpha_{\mathrm{v}}, \alpha_{3} / \alpha_{5}$, $\beta_{1}$, and $\beta_{3}$. Ando and Kamiya ${ }^{17}$ also showed that $\beta_{1}$ integrin is the signal-transducing mechanism for shear stress within endothelial cells. Consequently, the population of integrins may vary among endothelial cells because of different stress, and the degree of Gal staining may vary accordingly.

Regardless of the exact mechanism for differential $\alpha$ Gal expression, the absence of $\alpha$-Gal on porcine valvular endothelium protects the leaflets from xenoantibody-triggered rejection. To the best of our knowledge, there has been no published report describing the immunopathology of fresh porcine valves in human subjects or primates. More studies in this area are warranted to realize the potential of fresh porcine valve prostheses.

\section{REFERENCES}

1. Edmunds LH Jr, Cohn LH, Weisel RD. Guidelines for reporting morbidity and mortality after cardiac valvular operations. J Thorac Cardiovasc Surg 1988;96:351-3.

2. Adams DH, Chen RH, Kadner A. Cardiac xenotransplantation: clinical experience and future direction. Ann Thorac Surg. In press.

3. Galili U, Clark MR, Shohet SB, Buehler J, Macher BA. Evolutionary relationship between the natural anti-Gal antibody and the Gal alpha 1-3Gal epitope in primates. Proc Natl Acad Sci U S A 1987;84:1369-73.
4. Mitchell RN, Jonas RA, Schoen FJ. Pathology of explanted cryopreserved allograft heart valves: comparison with aortic valves from orthotopic heart transplants. J Thorac Cardiovasc Surg 1998;115:118-27.

5. Iben AB, Pupello DF, Holmes SL. The histologic and hemodynamic evaluation of viable heterograft valves. J Thorac Cardiovasc Surg 1971;61:556-60.

6. Adams DH, Chen RH, Kadner A, Naficy S. Technique for heterotopic pig heart xenotransplantation in primates. Ann Thorac Surg 1999;68:265-8.

7. Chen RI-I, Mitchell RN, Kadner A, Adams DH. Differential galactose $\alpha(1,3)$ galactose expression by porcine cardiac vascular endothelium. Xenotransplantation 1999;6:169-72.

8. Duran CG, Gunning AJ. Heterologous aortic-valve transplantation in the dog. Lancet 1965;2:114-5.

9. Binet JP, Duran CG, Carpenter A, Langlois J. Heterologous aortic valve transplantation. Lancet 1965;2:1275.

10. Paneth M, O'Brien MF. Transplantation of human homograft aortic valve. Thorax 1966;21:115-7.

11. O'Brien MF. Heterograft aortic valves for human use. J Thorac Cardiovasc Surgery 1967;53:392-7.

12. Hamilton DI, Gerbode F. Mitral valve replacement in dogs using pig aortic valve heterografts. Thorax 1968;23:239-48.

13. Martin-Mondiere CF, Caprani A, Desgranges PC, Loisance DY, Charron DJ. Shear stress affects expression of major histocompatibility complex antigens on human endothelial cells. ASAIO Trans 1989;35:288-90.

14. Ando J, Tsuboi H, Korenaga R, et al. Down-regulation of vascular adhesion molecule-1 by fluid shear stress in cultured mouse endothelial cells. Ann NY Acad Sci 1995;748:148-57.

15. Vanhove B, Sebille F, Cassard A, Charreau B, Soulillou JP. Transcriptional and posttranscriptional regulation of alpha 1,3galactosyltransferase in activated endothelial cells results in decreased expression of Gal alpha 1,3Gal. Glycobiology 1998;8:481-7.

16. Holzknecht ZE, Platt JL. Identification of porcine endothelial cell membrane antigens recognized by human xenoreactive natural antibodies. J Immunol 1995;154:4565-75.

17. Ando J, Kamiya A. Flow-dependent regulation of gene expression in vascular endothelial cells. Jpn Heart J 1996;37:19-32. 